\title{
Empirical Research on FDI, Environmental Regulation and Industrial Structure Upgrading
}

\author{
Hua Xiang ${ }^{1}$ and Tian Guixian ${ }^{2}$ \\ 1.Dongchang College of Liaocheng University China,100875 \\ 2. School of Business, Pingxiang University China,337055
} Keywords: Foreign direct investment; Environmental regulation; Industrial upgrading; Spatial
durbin model

\begin{abstract}
On the basis of new geographical economics, this paper considering the spatial factors, the interaction of FDI and environmental regulation and their lag effect, constructed a spatial Durbin model, using the panel data of China's 30 provincial panel data from 2004 to 2014, empirical analysis of the relationship between FDI, environmental regulation and the upgrading of the industrial structure. The results showed that: FDI, environmental regulation has significant spatial spillover effects on the industrial structure upgrading, and the interaction between environmental regulation and FDI is negative, which confirms the evidence of the existence of "pollution heaven hypothesis" in China. Finally, we give the corresponding policy recommendations, in order to provide theoretical and practical guidance for the upgrading of China's industrial structure.
\end{abstract}

\section{Question Arising and Existing Research and Analysis}

To promote the industrial structure upgrading from the perspective of the supplier's party is one of the key contents of Advice of CPC Central Committee on the Plan for the Thirteenth Five-Year National Economic and Social Development. It is also the main approach to deal with the excessive productivity and transform economic development motivation. Based on existed research, FDI perfects the technology in the industry, points the trend and facilitate the industrial structure upgrading of the host country through technology spillover, capital supply, foreign trade and other ways. From the point of view of technology spillover, FDI promotes the regional industrial structure upgrading through horizontal and vertical spillover; From the view of capital supply, FDI accelerate the industrial structure adjustments and upgrading through supply effect, industrial competition optimization and correlative effect among industries. From the perspective of foreign trade, FDI asserts direct or indirect influence on the industrial structure optimization by trade substitution, creation, and supplement as well as market expansion. Also, there are related researches which indicates the influence of FDI on the industrial upgrading is insignificant, or even negative. Julan Du emphasizes that FDI has positive and significant vertical spillover effect, but the horizontal spillover effect is not significant. Besides, the overflow of FDI will lead the host country into the trap of "comparative advantage", "supporting production" and "international outsourcing", which will hinder the development of the host country. ${ }^{[1]}$

The conclusions concerning the influence of FDI upon the industrial structure upgrading of the host country are not consistent, which has intrigued the interest of many researchers. Some researchers attach great importance to the system, and consider it the most important factor for the spillover effect of FDI. Under the background of regulations, there are significant differences in the inflow cause, characteristics of FDI from the conclusions drawn from classic FDI theories. Since our country is experiencing the "new normal" of economic transformation, the spillover of FDI will definitely be influenced by the environment and systems. In theory, environment regulation has actually affected the industrial structure upgrading of the host country through market demand, technological innovation and international trade, etc. Practically speaking, since FDI has mobility, it will transfer as the environment or the policy of the host country change or there are places with better comparative advantage. Therefore, the downfall of regional industrial cluster or the 
non-stable fluctuation of regional economy. As a result, we need to pay attention to the interaction between the FDI and environment regulation so that we can figure out the most practical way for industrial structure upgrading.

Different voices have been expressed in current literature involving the discussion of environment regulation effect on the spillover effect of FDI. Some researchers think that strict environment regulations will affect the cost of the enterprise in the short term. But from the long-term perspective, they will stimulate the innovation of the enterprises and influence the technological spillover effect of FDI, thus promoting regional industrial structure adjustments and upgrading. Other researchers think that the environment limitations in developing countries are relatively less so that there are more abundant environment factors, which makes environment the comparative advantage. In this case, the developing country will produce more and more products with pollution to expand exports. In the meantime, the industry with pollution in the developed country will be transferred to those developing countries with abundant environment resources. Munasinghe found out that Japan tended to encourage local industry with pollution to transfer to other Asian countries. ${ }^{[2]}$ Chen Gang has carried out empirical analysis and proved the relations between FDI and environment regulations. The result shows that the environment regulations have greatly hindered the inflow of FDI. The governments of other competitive regions can attract more FDI inflow by lowering the requirements for the environment. As a result, our country has become the "ideal sanctuary" of enterprises with polluted production. ${ }^{[3]}$

The inconsistent conclusions concerning the interaction between the FDI and the environment regulation has indicated that the traditional researches have neglected the connection between the region and the space and do not apply for the situation in which governments or regions compete for FDI resources or the enterprises can enter regions with less strict environment regulations (pollution sanctuary hypothesis).

Under the above-mentioned background, some researchers have discussed the spatial spillover effect of FDI and environment regulation on industrial structure upgrading from the perspective of spatial associations. Blonigen, Ellis \& Fausten have empirically analyzed the FDI spillover effect in cases where there were inflow of foreign investment into the US as well as cases when the US is investing in foreign countries. The research shows that the third-party market countries with relatively large scale invest the most in the US. That is to say, the inflow of FDI into the US has shown significant spatial spillover effect. ${ }^{[4]}$.

Through a general review of domestic and foreign literature of this topic, even though traditional researches have shown the influence of FDI and environment regulation on the industrial structure upgrading and have provided ample materials and references, there are still some weakness and limitations. First of all, in traditional studies, the FDI spillover effect is limited in independent regions, while the geographical and spatial factors are ignored. "The Porter Hypothesis" emphasizes that the environment regulations have actually encouraged the innovation of many enterprises and will then lead to industrial structure upgrading. However, in developing countries, rather than industry upgrading, the competitions among the governments may cause the transfer of the industry instead. If we look at the FDI and its spillover effect from a systematic view of regional connection, we can fit the requirements of the current policies for attracting foreign investment and thus facilitate the industrial upgrading. Secondly, the traditional studies neglected role of the interaction between FDI spillover effect and environment regulation in the process of industrial structure upgrading. "Polluted Paradise" Hypothesis emphasizes that the development countries could be the sanctuary of polluting enterprises, which also indicated that the competitions among the involved countries and regions might provide more choices in transfer for those polluting enterprises. With the environment regulations, the FDI tends to focus more on resources, rather than the local industrial structure upgrading, which will restrain the technological spillover effect of FDI. Taking the interaction between environment regulations and FDI is beneficial to realize goals of both FDI inflow and environment regulations. Thirdly, traditional studies neglected the lag effect that FDI and environment regulations have on the industrial structure upgrading. There are some time-lag from the inflow of FDI, the implementation of environment regulations, and industrial structure 
upgrading. Such negligence may cause some bias in the research conclusions.

Based the above-mentioned analysis, by applying the panel data of provincial level in 2004 to 2014, this paper intends to take the new economic and geographical theories, the spatial factors, the interaction between FDI and environment regulation and the lag effect into consideration to empirically analyze the mechanism among FDI, environment regulations and industrial structure upgrading. The factors influencing local industrial structure upgrading are also explored, which will provide theoretical and practical guidance for the industrial structure upgrading caused by FDI inflow and environment regulations.

\section{Model Design and Spatial Econometric Analysis}

\section{Spatial Econometric Model}

The non-homogeneity of the spatial distribution of FDI goes against the classic Gauss-Markov hypothesis. The Maximum Likelihood Estimation (MLE) method is needed to solve the problem of consistency and unbiasedness. Following spatial econometric models have been established based on the models and papers by Garretsen \& Peeters $(2007)^{[5]}$., and the statistical data from the provincial level during the period from 2004 to 2014.

$$
\mathrm{I}_{\mathrm{it}}=\beta_{0}+\beta_{1} \mathrm{WI}_{\mathrm{it}}+\beta_{2} \mathrm{FDI}_{\mathrm{it}}+\beta_{3} \quad \mathrm{ENV}_{\mathrm{it}}+\beta_{4} \quad \mathrm{CONX}_{\mathrm{it}} \quad+\beta_{5}\left(\mathrm{FDI}_{\mathrm{it}}+\quad \mathrm{ENV}_{\mathrm{it}}\right)+\quad \varepsilon_{\mathrm{it}}
$$

(1)

$\varepsilon_{\mathrm{it}} \in\left(0, \sigma_{\varepsilon}\right)$

$\mathrm{I}_{\mathrm{it}}=\beta_{0}+$

$\beta_{2} \mathrm{FDI}_{\mathrm{it}}+\beta_{3}$

$\mathrm{ENV}_{\mathrm{it}}+\beta_{4}$

$\mathrm{CONX}_{\mathrm{it}}$

$+\beta_{5}\left(\mathrm{FDI}_{\mathrm{it}}+\right.$

$\left.\mathrm{ENV}_{\mathrm{it}}\right)+$

$\varepsilon_{\mathrm{it}}$

(2)

$\varepsilon_{\mathrm{it}}=\lambda \mathrm{W} \varepsilon_{\mathrm{it}}+\mu_{\mathrm{it}}, \mu_{\mathrm{it}} \in\left(0, \sigma_{\varepsilon}\right)$

$\mathrm{I}_{\mathrm{it}}=\beta_{0}+\beta_{1} \mathrm{WI}_{\mathrm{it}}+\left[\beta_{2} \mathrm{FDI}_{\mathrm{it}}+\beta_{3} \mathrm{ENV}_{\mathrm{it}}+\beta_{4} \mathrm{CONX}_{\mathrm{it}}+\beta_{5}\left(\mathrm{FDI}_{\mathrm{it}}+\mathrm{ENV}_{\mathrm{it}}\right)\right]+\mathrm{W}\left[\theta_{2} \mathrm{FDI}_{\mathrm{it}}+\theta_{3} \mathrm{ENV}_{\mathrm{it}}+\theta_{4} \mathrm{CONX}_{\mathrm{it}}\right.$ $+\theta_{5}\left(\mathrm{FDI}_{\mathrm{it}}+\right.$ $\left.\left.\mathrm{ENV}_{\mathrm{it}}\right)\right]$

(3)

$\varepsilon_{\mathrm{it}}=\lambda \mathrm{W} \varepsilon_{\mathrm{it}}+\mu_{\mathrm{it}}$

Model (1) is the spatial lag model; Model (2) is spatial error model; Model (3) is spatial tobit model, which includes the item of spatial lag and the item of spatial error.

\section{Variable Declaration}

$\mathrm{I}_{\mathrm{it}}$ represents the industrial structure of region $i$ in the $t^{\text {th }}$ year. It is in the form of the percentage of the production value of the tertiary industry out of the GDP; W represents the spatial weight matrix. By integrating the geographical and economic factors, the spatial weight matrix has been established. The spatial weight matrix $\mathrm{W}=\alpha \mathrm{W}_{1}+(1-\alpha) \mathrm{W}_{2}$, in which $\mathrm{W}_{1}$ is geographic adjacent matrix, and $\mathrm{W}_{2}$ is economic distance matrix. We set $\alpha=0.5$. FDI $\mathrm{Fit}_{\mathrm{it}}$ represents for the total FDI in region $i$ in the $t$ th year. $E N V_{i t}$ represents the environment regulation in region $i$ in the $t$ th year. $I$ have used the wastewater discharge rate, sulfur dioxide removal rate, and solid waste multipurpose utilization rate of each province as 3 indexes to refect the environment regulation level. CONX $\mathrm{it}_{\mathrm{i}}$ represents the control variable in region $i$ in the $t$ th year. It includes the following: financial revenue, population, population density. FDIit* ENVit represents for the interaction between FDI and environment regulations.

Confirmation of lag phase. Adopt gray relation technology to confirm the lag phase of FDI and environmental regulation in affecting the upgrading of industrial structure. Adopt gray relation technology to separately analyze the gray relation coefficient of FDI and environmental regulation (lag phase 1-4) to industrial structure upgrading, and it's discovered that FDI and environmental regulation with two lag phases has the highest degree of relation to industrial structure upgrading, hence it's confirmed that FDI and environmental regulation has two lag phases.

\section{Model Estimation}

This paper adopts panel data of 30 provincial districts in China from 2004 to 2014, to regress model (1)--(4) . Regression result please see Figure (1)--(2). 
Table1. Model OLS regression results

\begin{tabular}{|c|c|c|c|c|}
\hline $\begin{array}{l}\text { variable } \\
\text { fixed }\end{array}$ & Pooled OLS & Spatial fixed effects & Time fixed effected & Two way \\
\hline Intercept & -0.07 & ----- & ----- & \\
\hline $\begin{array}{l}\mathrm{FDI}_{\text {it }} \\
0.17 * *\end{array}$ & $0.83 * * *$ & $0.17 *$ & $0.83 * * *$ & \\
\hline $\begin{array}{l}\mathrm{ENV}_{\text {it }} \\
0.03^{*}\end{array}$ & $-0.04 * *$ & 0.03 & $-0.04 * *$ & \\
\hline $\begin{array}{l}\mathrm{FDI}_{\text {it }} * \mathrm{ENV}_{\text {it }} \\
\mathrm{Fin}_{\text {it }} \\
-0.35\end{array}$ & $\begin{array}{l}-0.33 * * \\
-1.41 * * *\end{array}$ & $\begin{array}{l}-0.18 * \\
-0.35 * *\end{array}$ & $\begin{array}{l}-0.33 * * \\
-1.41 * * *\end{array}$ & -0.18 \\
\hline $\begin{array}{l}\mathrm{PeO}_{\text {it }} \\
0.03^{*}\end{array}$ & $0.69 * * *$ & $0.02 *$ & $0.69 * * *$ & \\
\hline $\begin{array}{l}\operatorname{Den}_{i t} \\
\mathrm{R}^{2}\end{array}$ & $\begin{array}{r}-0.03 \\
0.56\end{array}$ & $\begin{array}{r}0.03 \\
0.67\end{array}$ & $\begin{array}{r}-0.03 \\
0.55\end{array}$ & 0.04 \\
\hline $\begin{array}{l}0.06 \\
\log \mathrm{L} \\
143.91\end{array}$ & -266.46 & 143.91 & -266.46 & \\
\hline LM spatial lag & 0.93 & 0.63 & 0.92 & 0.63 \\
\hline LM spatial error & 22.60 & 13.36 & 22.43 & 13.36 \\
\hline Robust LM spatial lag & 4.47 & 1.72 & 4.47 & 1.72 \\
\hline $\begin{array}{l}\text { Robust LM spatial error } \\
14.45\end{array}$ & 26.14 & & & 25.98 \\
\hline
\end{tabular}

Note: $* * *$ refers to examination at $1 \%$ significance level; ** refers to examination at $5 \%$ significance level; * refers to checking at $10 \%$ examination level. All the regression coefficients are standardized coefficient.

From the results of examination towards various panel regression data as shown in Figure (1) we can see that there's no spatial effect, error effect or spatial lagged effect between LM spatial lag and LM spatial error, Robust LM spatial lag examination and Robust LM spatial error. Therefore, we shall adopt maximum likelihood method (ML) to estimate model (1)--(4).

Table 2. Model regression results

\begin{tabular}{|c|c|c|c|c|}
\hline variable & Modell & Model2 & Model3 & Model4 \\
\hline $\mathrm{FDI}_{\mathrm{it}}$ & $0.77 * * *$ & $0.78 * * *$ & $0.39 * * *$ & $0.64 * * *$ \\
\hline $\mathrm{ENV}_{\text {it }}$ & $-0.06^{*}$ & $-0.09 *$ & $-0.07 * * *$ & $-0.02 *$ \\
\hline $\mathrm{FDI}_{\mathrm{it}} * \mathrm{ENV}_{\mathrm{it}}$ & $-0.27 *$ & $-0.37 *$ & $-0.39 * *$ & $-0.49 * *$ \\
\hline Fin $_{\text {it }}$ & $-1.41 * * *$ & $-1.57 * * *$ & $-0.41 * * *$ & $-1.15 * * *$ \\
\hline $\mathrm{PeO}_{\text {it }}$ & $0.71 * * *$ & $0.69 * * *$ & $0.12 * * *$ & $0.60 * * *$ \\
\hline $\operatorname{Den}_{\mathrm{it}}$ & -0.03 & 0.08 & 0.03 & 0.01 \\
\hline $\mathrm{W}^{*} \mathrm{FDI}_{\mathrm{it}}$ & --- & --- & $-0.27 *$ & -0.02 \\
\hline $\mathrm{W}^{*} \mathrm{ENV}_{\mathrm{it}}$ & --- & --- & $-0.03 *$ & -0.04 \\
\hline $\mathrm{W} *\left(\mathrm{FDI}_{\mathrm{it}} * \mathrm{ENV}_{\mathrm{it}}\right.$ & --- & --- & $-0.24 *$ & -0.31 \\
\hline $\mathrm{W}^{*} \mathrm{Fin}_{\mathrm{it}}$ & --- & --- & -0.57 & -0.76 \\
\hline $\mathrm{W}^{*} \mathrm{Peo}_{\text {it }}$ & --- & --- & -0.09 & -0.12 \\
\hline $\mathrm{W}^{*} \operatorname{Den}_{\text {it }}$ & --- & --- & 0.33 & 0.03 \\
\hline $\mathrm{R}^{2}$ & 0.56 & 0.61 & 0.98 & 0.53 \\
\hline Log-Likehood & -265.91 & -143.77 & 161.62 & -258.85 \\
\hline
\end{tabular}

Note: the same as above

Based on the regression result shown in Figure 2, and compare the Log-Likehood values of Model 1--4, we can discover that Model 3 is the optimal model. Regression result of Model 3 shows that $F D I_{i t}$ - has positive coefficient, and $W E N V_{i t-}$ has negative coefficient, indicating that the effect of industrial structure upgrading is influenced by positive local FDI inflow and negative environment regulation. In the meanwhile, the interaction of FDI and environment regulation has negative influence to the effect of industrial structure upgrading, indicating the discrepancy of environment regulation policies at different districts, making the FDI flow characteristics incline to "pollution haven" hypothesis.

The coefficients of $W \times F D I_{i t-}$ and $W \times E N V_{i t-}$ are both negative, which indicate not only that 
there's significant spatial spillover effect between FDI and environment regulation, but also that the effect of local industrial structure upgrading is influenced by FDI and environment regulation at adjoining areas. In other words, foreign investment attracting policies and environment regulation policies at adjoining areas have negative effects to industrial structure upgrading effect at local area. To be specific, when the ability of adjoining area in attracting foreign investment is strong, FDI inflow to local area may be restrained, hence weaken the effect of industrial structure upgrading. And when ability of adjoining area in attracting foreign investment is weak, it might lead to the migration of industries to local area, furthermore obstruct the upgrading of local industrial structure.

\section{Policy Suggestions}

According to the analysis, under the combined action of economic effect and spatial effect, the effect of our industrial structure upgrading is not only affected by factors e.g. local FDI, environment regulations, etc., but also by FDI and environment regulations at adjoining areas. Following suggestions on policies are presented to actualize local industrial structure upgrading and transform the economic development pattern.

First, different areas shall make overall coordination in terms of their foreign investment attracting policies to promote the technology spillover effect of FDI. Such approach requires the central government to change the situation that current government official assessment are simply focused on foreign investment utilization as the single index, and turn to focus on the quality and efficiency of foreign investment utilization. Specifically speaking, local government shall on the one hand continue to strengthen its guidance and management to foreign investment attraction, improve the threshold of foreign capital entrance, and guide FDI to focus on technology innovation, hence play the technology spillover effect practically. On the other hand, local government shall control the quality of foreign investment utilization, to make sure that the allocation and technical content of foreign investment comply with local planning regarding industrial structure adjustment. Also, local government shall establish differentiated foreign investment utilization scheme and regional coordination mechanism. From the aspect of overall country, we should adjust the quality of foreign investment utilization at different districts, and give play to the effect of local industrial structure upgrading.

Second, "Pollution haven" hypothesis exists in China to a certain degree, which indicates the disordered competition between local governments and lack of environment regulation incentive. Playing the incentive role of environment regulation to industrial structure upgrading calls for concerted action of different local governments to jointly prevent migration of pollution factories rather than technology upgrading. Furthermore, since there's certain time-lag between environment regulation policies and the industrial structure upgrading effect, local governments shall strengthen the superimposed effect and composite effect of policy designing characteristics e.g. strength of environment policies, policy stability, policy guidance, etc. to industrial structure upgrading. Also, different areas shall adjust their measures to local conditions, observe to the concept of "fair taxation, seek common points while reserving difference", adopt environment regulation approaches e.g. imposing environment tax, promoting carbon emission trading and green consumption, etc., to improve the function of environment regulations to the effect of industrial structure upgrading.

Third, implement environment regulation system innovation and promote the positive interaction between FDI and environment regulations. Currently, the interaction between FDI and environment regulations shows negative effect to industrial structure upgrading. Possible reason is that FDI focuses on seeking resources and tend to pay attention to blockade and protection on techniques. To actualize the positive interaction between FDI and environment regulations, firstly, the formulation of environment regulations shall fully take into consideration of environmental protection and carrying capacity of industries and enterprises; secondly, we shall implement differentiated environment regulations based on the diversified phase of industrial innovation activities, and implement more strict environment regulations to innovation activities at the technological development phase; thirdly, we shall guide foreign capital to invest in industrial upgrading and reconstruction projects, to play the technological effect of FDI, achieve the dual goals of foreign 
investment attraction and environment regulations, and realize "win-win" of both environment protection and technological innovation.

\section{References}

[1] Julan Du, Yi Lu, Zhigang Tao. Ecomomic Institutions and FDI Location Choice: Evdience From US Multinationals in China[J]. Journal of Comparative Economics, 2008, (36): 412-429.

[2] Munasinghe M. Is environmental degradation an inevitable consequence of economic growth: Tunneling through the environmental Kuznets curve [J]. Ecological Economics, 1999, 29 ( 1 ) : $89-109$.

[3] ChenGang. The Competition for FDI, Environmental Regulation, and Pollution Haven [J]. World Economy Study, 2009 ( 6)3 -743.(in Chinese)

[4] Blonigen A, Ellis J, Fausten D. Industrial groupings and foreign direct investment[J]. Journal of International Economics, 2005, 65(1):75-91.

[5] Ghinamo M, Panteghini P M, Revelli F. FDI Determination and Corporate Tax Competition in a Volatile World[J]. International Tax \& Public Finance, 2007, volume 17(5):532-555.

[6] Yu D, Peng L. When does Inferring Reputation Probability Countervail Temptation in Cooperative Behaviors for the Prisoners' Dilemma Game? [J]. Chaos, Solitons \& Fractals, 2015, 78: 238-244. 